LAWRENCE LIVERMORE N A T IO N A L LABORATORY
The Lawrence Livermore National Laboratory DOE-STD-3013 Surveillance Program for the Storage of Plutonium Packages

D. C. Riley

January 7, 2005 
This document was prepared as an account of work sponsored by an agency of the United States Government. Neither the United States Government nor the University of California nor any of their employees, makes any warranty, express or implied, or assumes any legal liability or responsibility for the accuracy, completeness, or usefulness of any information, apparatus, product, or process disclosed, or represents that its use would not infringe privately owned rights. Reference herein to any specific commercial product, process, or service by trade name, trademark, manufacturer, or otherwise, does not necessarily constitute or imply its endorsement, recommendation, or favoring by the United States Government or the University of California. The views and opinions of authors expressed herein do not necessarily state or reflect those of the United States Government or the University of California, and shall not be used for advertising or product endorsement purposes.

This work was performed under the auspices of the U.S. Department of Energy by University of California, Lawrence Livermore National Laboratory under Contract W-7405-Eng-48. 


\section{The Lawrence Livermore National Laboratory DOE-STD-3013 Surveillance Program for the Storage of Plutonium Packages}

Written by:

David Riley

$\mathrm{Pu}$ Chemical Processing

Nuclear Materials Technology Program

Ken Perkins

Program Leader

Nuclear Materials Technology Program

Mark Martinez

Program Leader

Nuclear Materials Technology Program

Karen Dodson

Associate Program Leader for Pu Chemical Processing

Nuclear Material Technology Program 


\section{$\underline{\text { REVISION LOG }}$}

Revision

Number

0
Effective

$\underline{\text { Date }}$

November 17, 2004 Initial Release
Pages

Affected

NA 


\section{The Lawrence Livermore National Laboratory DOE-STD-3013 Surveillance Program for the Storage of Plutonium Packages}

\section{Summary}

This document presents a site-specific DOE-STD-3013 (3013) surveillance program for 3013 material stored at Lawrence Livermore National Laboratory (LLNL) in the B332 Plutonium Facility. The 3013 standard requires the development of a surveillance program to assure the long-term safety of plutonium storage in 3013 compliant containers.

A complex-wide Integrated Surveillance Program in Support of Long-Term Storage of Plutonium-Bearing Materials (ISP)(LA-UR-00-3246, Revision 1, March 2001) has been developed to give guidance on an acceptable surveillance approach and to set up a mechanism to integrate surveillance activities and facilitate the sharing of lessons learned. This LLNL 3013 surveillance program has been developed following guidelines established for Storage Sites in the ISP and is sufficient for the storage in the LLNL Plutonium Facility.

The LLNL 3013 surveillance program must be coupled with the DOE complex wide Materials Identification and Surveillance (MIS) program and the ISP led by Savannah River Site (SRS). These programs support the technical basis for continuing safe storage of plutonium packages and provide the technical basis for the limited scope of the site-specific LLNL 3013 surveillance program.

The LLNL 3013 surveillance program calls for surveillance of 3013 packages to begin approximately three years after packaging of the first oxide. One percent of the stored packages per year will be randomly selected and nondestructively examined (NDE) by LLNL per the guidelines of the ISP. Additional packages may be selected for NDE if recommended by the ISP Steering Committee and agreed upon by the MIS Working Group. One selected package will be shipped to SRS for destructive analysis each year starting when SRS can receive them. This is expected to be in FY2007. We expect to store a maximum of 4003013 packages. This would result in an expected maximum of 4 surveillances per year.

The activities outlined in the program evolved from the current understanding of materials behavior and may be significantly modified as the knowledge base increases. This surveillance program is a living document that will be revised based on information gathered through this program as well through the MIS, ISP and lessons learned from other DOE storage sites.

\section{Programmatic Approach for Surveillance}

The basic approach to meeting the operational surveillance requirements necessary to support the requirements of DOE-STD-3013 is to utilize the current understanding of the material/component behavior while expanding this knowledge base through this site specific program, the MIS program, and the ISP. The Los Alamos National Laboratory (LANL) MIS Shelf-Life Surveillance Program includes testing and surveillance of inner 3013 packaged materials and SRS will lead the destructive assay of outer 3013 containers. The ISP coordinates 
all testing and surveillance of 3013 packaged material to assure safe storage and to minimize total cost of surveillance for the DOE Complex. This approach reduces the necessity for the annual removal, evaluation, and replacement of large numbers of packages from the LLNL vault storage and is consistent with the ISP.

\section{Prerequisites, Baseline and Procedures}

In the initial stages of the operational surveillance program., prerequisites, baselines and operating procedures must be developed that identify the initial condition of the storage inventory, specify requirements for surveillance activities and provide acceptance criteria. Baselines will establish the physical characteristics, including normal variations, of the 3013 containers. Baselines will serve as the standard for comparison for packages in the LLNL 3013 inventory.

\section{Container Baseline}

LLNL will provide baseline information for the 3013 container and contents. This information will include baseline radiographs and initial lid deflection radiographs for the inner 3013 can after welded into an outer 3013 can. Baseline information for the outer 3013 container will be established to provide acceptance criteria for non-destructive surveillance activities. A baseline radiography measurement will be obtained within 30 days of welding the inner 3013 can into the outer 3013 can.

\section{$\underline{\text { Selection of Surveillance Samples }}$}

Selection of surveillance samples will be accomplished in cooperation with the ISP Steering Committee and the MIS Working Group and will be accomplished as defined by the ISP.

\section{Operational Surveillance 3013 Packages Stored in the Plutonium Facility}

Operational surveillance will validate the condition of representative samples from the inventory of 3013 plutonium packages stored in the Plutonium Facility. The sample population is divided into a number of sub populations. The initial sub populations are: innocuous, pressure causing, corrosive, and "pressure and corrosive."

Knowledge of the condition of the plutonium package inventory is essential to the continuing safety of plutonium storage operations. The safe storage of 3013 plutonium packages at LLNL requires that the integrity of the 3013 packages be maintained throughout the storage period. The technical basis to assure the continuing integrity includes surveillance assessments of the condition of representative packages. The ISP and MIS programs complement/supplement the assessments outlined in the LLNL 3013 Surveillance Program.

Beginning approximately 36 months after packaging of the first oxide, 1\% of the stored 3013 packages per year will be examined. The initial surveillance activities will include nondestructive evaluation of the 3013 package. In addition, one 3013 package will be sent to SRS for destructive evaluation every year starting when SRS can accept them. This is expected to be 
in FY2007. Surveillance activities are not needed until three years after packaging the first oxide because of the 3013 stabilization process, the robustness of the 3013 packages and the experience/ engineering judgment that early age/storage-related failures in the packages will not occur. The quality assurance programs will minimize the probability of failures due to poor packaging and the DOE 3013 standard and the SRS Stabilization and Packaging Requirements for Plutonium Bearing Materials for Storage, G-ESR-G-00035, will assure that a properly packaged system is robust.

\section{Operational Package Surveillance}

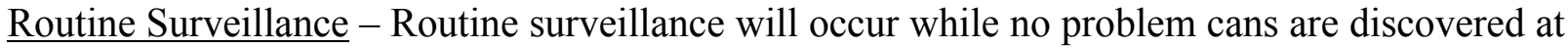
any of the sites based on information collected by the ISP and MIS programs. One percent of the stored 3013 packages will be evaluated annually starting approximately 3 years after packaging the first oxide was initiated. Packaging at LLNL was initiates in August 2003. Therefore, the first operational surveillance will occur approximately in August 2005. The sample packages will be selected based on information emerging from ISP and MIS programs and the information provided by the packaging site.

1. Evaluate $1 \%$ of stored packages non-destructively each year,

2. Determine condition of 3013 container by visual examination,

3. Determine integrity of 3013 container by contamination survey,

4. Weigh the 3013 container and comparing with baseline weight,

5. Determine 3013 inner can lid deflection (pressure) by radiography,

6. Determine plutonium-bearing material condition by radiography,

7. Confirm contents by gamma isotopic analysis and calorimetry,

8. Transport one package to SRS for destructive examination every year starting when SRS can receive it,

9. Return the nondestructive analysis packages to storage,

10. Document surveillance results, and

11. Transfer surveillance results to SRS for inclusion in the site-wide surveillance database.

Immediate Assessment

If a problem in the storage inventory is identified, review and evaluation committees will be selected through interactions among DOE, WSRC, LANL, and LLNL personnel. This is also applicable if any potential problems are uncovered by the routine evaluations of selected packages.

Documentation of Results

Annual reports on Routine Surveillance and reports on the results of Immediate Assessments will be generated and submitted to the ISP and MIS Programs. It is expected that annually the ISP and/or MIS programs will generate a report about all containers examined that year at all storage sites. This information will be evaluated for impact on the plan. In addition, an electronic file containing the NDE data from a surveyed item will be submitted to SRS for inclusion in a sitewide surveillance database. 